\title{
Estimation of Cumulative Energy Demand and Green House Gas Emissions of Ethanol Foamed WMA using Life Cycle Assessment Analysis
}

Mohd Rosli Mohd Hasan ${ }^{1}$, Zhanping You, Ph.D., P.E $E^{2, *}$

${ }^{1} \mathrm{PhD}$ Candidate, Department of Civil and Environmental Engineering, Michigan Technological University, 1400 Townsend Drive, Houghton, MI 49931, USA

${ }^{2}$ Professor of Transportation Engineering, Michigan Technological University, Department of Civil and Environmental Engineering, 1400 Townsend Drive Houghton, MI 49931 USA *Corresponding Author:

Tel: (906)487-1059, Fax: (906)487-1620, Email: zyou@ mtu.edu

\begin{abstract}
The purpose of this project is to evaluate the possibility of using ethanol as a foaming agent for low emission asphalt technology via Life Cycle Assessment (LCA) analysis. LCA analysis was conducted at two different stages. Firstly, the analysis was performed to estimate the energy consumption and $\mathrm{CO}_{2}$ emission in the cradle to gate stages incorporating the effects of various foaming agent contents. In the second assessment, the analysis attempts to incorporate the required information based on the available published papers to get a clear idea about the energy consumption and GHG emission involved in all stages from the raw materials production to the end of life of asphalt pavement. The scope and boundaries of this analysis have been set based on several assumptions made prior to performing the analysis. LCA software, SimaPro 7.3, was used to estimate the cumulative energy demand and global warming potential (GWP) of Ethanol-foamed Warm Mix Asphalt (EWMA) and compare these to the results of Hot Mix
\end{abstract}


Asphalt (HMA) and Water-foamed Warm Mix Asphalt (WWMA). Eco-Indicator 95 analysis was also conducted to establish the weighting factors for the various environmental effects of each asphalt mixture. Based on the results, it was found that the EWMA performed better in terms of energy demand, and lowered GHG emissions compared to HMA and WWMA. EWMA has high potential to reduce the detrimental impacts from the asphalt pavement industry based on Eco-Indicator 95 analysis, which has a lower impact in terms of GHG emissions, ozone layer depletion, acidification, eutrophication, summer smog, and winter smog, as well as energy resources.

Keywords: Low emission asphalt, energy consumption, environmental benefits, human health, sustainable asphalt pavement 


\section{Introduction}

Energy consumption is one of the key elements in pavement construction that significantly

3 contributes to the entire construction cost. In conjunction with that, it is important to control the entire

4 construction cost, and to meet increasingly stringent environmental regulations using a green and energy

5 saving technology, which is known as warm mix asphalt (WMA). Formerly, this technology was

6 discovered by Professor Csanyi at Iowa State University in 1956 [1]. In his study, the foaming asphalt

7 was found to have great potential to use as a soil binder. Then, his invention was altered by

8 incorporating cold water instead of steam into the asphalt, and later licensed to Conoco Inc. to promote

9 foamed asphalt technology in the United States [2, 3]. In general, the foaming effect can be achieved by

10 introducing a small amount of water into the asphalt binder prior to mixing with aggregates during the

11 asphalt concrete production process [4]. The water creates a volume expansion of the binder that results

12 in foamed asphalt, as well as improved the workability, and aggregate coating at lower temperature [5].

13 Currently, there are two techniques typically used in producing foamed WMA, which are foaming

14 admixture, and the free water system [6, 7]. The energy savings and emissions reductions introduced by

15 current foaming WMA technology could be enhanced if the production process is conducted at still

16 lower temperature settings, through application of ethanol-foamed WMA (EWMA). Generally, ethanol

17 can function in the same manner as water (in water-foamed WMA (WWMA)) and requires less energy

18 to foam, due to its lower boiling temperature, $78{ }^{\circ} \mathrm{C}$. Numerous bubbles will be generated by the

19 vaporized ethanol, which significantly increases the volume of foamed asphalt, hence lowering the

20 asphalt binder viscosity and improving the coating process of aggregates.

21 WMA using water as a foaming agent is one of the most commonly used WMA technologies in

22 the United States due to its cost-effectiveness. Generally, no extra additives are required and the water is

23 easier to handle and obtain [8]. The concept behind the foamed WMA is that the water turns into steam 
24 and disperses throughout the asphalt, and then the steam expands the volume of the binder. Currently,

25 numerous research projects are still going on prior to improving the performance of the foamed WMA

26 pavement. The list of currently available foamed WMA technologies is presented in Table 1 [9].

The life cycle assessment (LCA) is being accepted and used by the engineers and road industry

to assess environmental impacts based on the inventory of relevant energies, resource inputs and

30 environmental outputs $[10,11]$. The concept of LCA is not new and extensively applied to measure the

31 impacts of the entire process or production to the environment that linked to any activities from the

32 initial assembly of raw materials to the end-of-life of the product, which all residuals are returned to the

33 earth (landfill). This concept is referred as "cradle to grave" [11]. Based on Horvath and Hendrickson

$34[12]$ the phases in the LCA analysis can be categorized into five different stages for the entire life cycle

35 of a product:

36 i. Materials extraction phase

37 ii. Materials processing stage

38 iii. Product manufacturing stage

39 iv. Use phase

40 v. Disposal stage of the product, also referred as end-of-life

\section{2. Goals and Scopes}

The purpose of this project is to evaluate the possibility of using ethanol as a foaming agent to reduce the production temperature of asphaltic concrete. Through application of LCA, the overall life

45 cycle performance of EWMA could be understood and compared to two other types of asphalt 46 concretes. Application of ethanol in foamed WMA is believed to be able to greatly reduce the energy 
47 required and $\mathrm{CO}_{2}$ emission during the production and construction of the pavement, due to lower

48 temperatures during the production and construction processes. Analyses have been conducted at two

49 different conditions: 1) cradle to gate analysis for the foamed asphalt mixture prepared at different

50 temperatures and foaming agent contents, and 2) cradle to grave analysis to understand the overall

51 performance of each mixture type. The phases that involved in the cradle to gate analysis are the

52 materials extraction phase, materials processing stage, transportations of raw materials from producers

53 to the asphalt plant and production of the asphalt mixtures. In the cradle to grave analysis, evaluations

54 were only conducted on HMA that prepared at $160^{\circ} \mathrm{C}$, WWMA that was prepared at $110^{\circ} \mathrm{C}$ with $1 \mathrm{wt} \%$

55 water, and EWMA produced at $80^{\circ} \mathrm{C}$ with $1 \mathrm{wt} \%$ ethanol. The percentages of foaming agents were

56 computed based on the mass of asphalt binder. Several assumptions have been made prior to conducting

57 the LCA, such as:

58 1. All the pavement systems have a comparable service life of about 10 years.

592 2. The machineries that are used for the construction are the same.

603 3. The maintenance procedure and the performance of all systems are the same, without 61 consideration on the climate effects and volume of traffic.

62 4. The detailed information about all the systems has been selected based on the field evaluations 63 and experimental works as well as literature review from previous studies.

64 Through LCA analysis, the results for the different asphalt pavements could be compared 65 between each other in order to decide the best alternatives based on energy consumption, carbon 66 footprint, as well as impacts to the environment.

67

68 3. Methodologies and Data Inventories 
This analysis attempts to incorporate the required information as much as possible to get a clear

70 idea about the energy consumption and GHG emission involved in: 1) production (cradle to gate) stages,

71 2) and in the entire (cradle to grave) stages from the raw materials production to the end of life of

72 asphalt pavement. Fig. 1 shows the general LCA scope and boundaries that were considered in the

73 analysis of HMA pavement. Meanwhile, Fig. 2 presents the boundaries that were involved in conducting

74 the assessment on EWMA and WWMA. However, the LCA analysis in this study only takes into

75 consideration the surface (top) layer of the asphalt pavement structure and setting the rest of the

76 pavement structural (sub-grade, base, sub-base, road base) as consistent throughout the analysis. In

77 addition, the type of aggregate and binder grade used in the analyses were the same. Basically, in the

78 foamed WMA concrete, the water and ethanol were used to improve the ability of asphalt binders to coat

79 the aggregate particles at a lower temperature compared to the temperature that is used in the production

80 of conventional HMA. Most of the data involved in the analysis were based on a paper that was

81 published by Chehovits and Galehouse [13] and data which was available in the SimaPro 7.3.

82 In the case of this study, the functional unit is based on one kilometer length of road (two-way

83 road with one lane each direction) and a lifetime of ten years for all three systems. Prior to calculating

84 the volume of asphalt content required for the production of each pavement types, the total width and

85 thickness of the pavement surface layer has been set at $7.5 \mathrm{~m}$ and $100 \mathrm{~mm}$, respectively. In addition, the

86 bulk specific gravity of pavement was assumed equal to 2.45 .

Tables 2 to 4 show the input that was incorporated in the LCA analysis of HMA, WWMA and

89 EWMA. The mass of materials adopted in the analysis is based on the Michigan Department of

90 Transportation (MDOT) design, which is about $93 \mathrm{wt} \%$ of aggregate, $5.5 \mathrm{wt} \%$ of asphalt binder and 1.5

91 wt\% filler material. All materials' masses were calculated based on total mass of asphalt concrete. The 
92 raw materials were transported from the nearest available sources in order to reduce the amount of

93 energy consumed and GHG gas emitted while transporting the material from the selected locations to

94 the asphalt concrete production plant in Hancock, Michigan. The locations and total distances required

95 in transporting all the materials are as shown in Fig. 3 and Table 2. Table 3 presents the energy

96 consumed during the production of asphalt concrete and energy required by the pumping system for

97 supplying the foaming agent to the mixing drum. Chehovits and Galehouse [13] mentioned that the

98 manufacturing process covers all steps including handling, storing, drying, mixing and preparation of

99 materials for installation. The manufacturing of HMA consumed about $275 \mathrm{MJ} / \mathrm{t}\left(160^{\circ} \mathrm{C}\right)$, followed by

100 WWMA with $234 \mathrm{MJ} / \mathrm{t}\left(130^{\circ} \mathrm{C}\right)$ and $161.6 \mathrm{MJ} / \mathrm{t}\left(110^{\circ} \mathrm{C}\right)$, while the energy consumptions for the EWMA

101 are $138.2 \mathrm{MJ} / \mathrm{t}$ and $95.8 \mathrm{MJ} / \mathrm{t}$ for the specimen prepared at 100 and $80^{\circ} \mathrm{C}$, respectively. Those adopted 102 energies were based on the interpolations of data referred from Chehovits and Galehouse [13]. When 103 producing the WMA using the asphalt foaming system, a separate device consisting of a storage tank 104 and high pressure pump is required to supply the foaming agent into the heated asphalt [9]. The energy 105 required in operating the high pressure pump is assumed to be approximately $4.94 \mathrm{~kW} / \mathrm{t}$ and $6.35 \mathrm{~kW} / \mathrm{t}$ for 106 the water and ethanol, respectively based on the available pump in the market. The input required for the 107 cradle to grave analysis, involving transporting asphalt mixture to the construction site, pavement 108 rehabilitation and waste scenario are presented in Table 4. The chip seal or seal coat has been used for 109 pavement rehabilitation, which is typically applied in the fourth and eighth years.

\section{$111 \quad 4 . \quad$ Results and Discussions}

112

1134.1 Energy Consumptions and $\mathrm{CO}_{2}$ Emissions during Production Stage 
115 applications of $1 \mathrm{wt} \%$ and $3 \mathrm{wt} \%$ of ethanol have increased the energy consumption of EWMA 116 production, which is associated with the delivery process of ethanol to asphalt production plant by 117 approximately $0.18 \%$. Meanwhile, about $0.36 \%$ higher energy is required for transporting raw material 118 prior to using $5 \mathrm{wt} \%$ ethanol as a foaming agent at both production temperatures, $80^{\circ} \mathrm{C}$ and $100^{\circ} \mathrm{C}$. The 119 applications of foaming WMA have lowered the cumulative energy demand for preparing asphalt 120 mixture as presented in Fig. 5. Based on the results, EWMA has a high potential to reduce the energy 121 consumption via lowering the manufacturing temperature. However, excessive amounts of ethanol 122 should be avoided to limit the total energy demand in the overall manufacturing process that is 123 contributed by the ethanol production. This involves cultivation of corn and manufacturing of ethanol 124 liquid. Prior to this, the application of 5\% ethanol should be avoided due to excessive amount of energy 125 consumption compared to HMA. However, to select an adequate temperature for EWMA mixture 126 production, it should be based on the sample performance either from the experimental works or field 127 trials. According to WWMA mixtures' energy consumption at both production temperatures $\left(110^{\circ} \mathrm{C}\right.$ and $128130^{\circ} \mathrm{C}$ ), higher amounts of foaming agents (water) do not considerably effect the amount of energy 129 required for the manufacturing process. Overall, each pavement presents a similar trend, whereas more 130 than $90 \%$ of energy was consumed during the manufacturing process of asphalt mixtures in the early life 131 of asphalt pavement. Fig. 6 shows the total energy demand for each asphalt mixture. It is found that 132 WMA technique can be applied to help support the sustainable development by lowering the energy 133 consumption in the asphalt pavement industry. Besides lowering the required energy for the heating and 134 mixing processes, WMA technology also results in lower aging factor that has significantly improved 135 the fatigue resistance of asphalt pavement [9], especially for the pavement that is placed in the hot 
136 climate regions. However, attention should be taken into account to avoid premature permanent 137 deformation especially in the beginning of service life [9].

141 WMA technologies has reduced the total $\mathrm{CO}_{2}$ emissions during preparation of asphalt mixture. The total 142 GHG emissions resulted from each pavement type are shown in Fig. 7. Based on the figure, it is found 143 that the amount of $\mathrm{CO}_{2}$ released from WWMA mixtures is constant even when a higher amount of water 144 is used. However, the $\mathrm{CO}_{2}$ emission of the specimen prepared using ethanol in EWMA is proportionally 145 increased when a higher amount of ethanol is used. This trend can be seen from the EWMA mixture 146 prepared at $80^{\circ} \mathrm{C}$ and $100^{\circ} \mathrm{C}$. The emission was generated during the ethanol's production in the factory 147 and while transporting it to asphalt plant was automatically considered in the SimaPro 7.3. Meanwhile, 148 the constant $\mathrm{CO}_{2}$ emission from WWMA mixtures is due to the application of water as foaming agent, 149 since water does not require transportation as tap water was used in the case of this study. Asphalt 150 mixture manufactured using foaming WMA technique and ethanol as foaming agent emit a significantly 151 lower amount of GHG, especially for the specimen prepared at $1 \%$ and $3 \%$ ethanol (based on the mass 152 of asphalt binder).

Fig. 8 shows that the EWMA has the lowest $\mathrm{CO}_{2}$ emission compared to WWMA and HMA, especially during asphalt mixture production stage. However, there are no considerable differences of $\mathrm{CO}_{2}$ emissions in all pavements during the transportation of raw materials to the asphalt plant. About 0.26\% (100 $\left.\mathrm{kg} \mathrm{CO}_{2} \mathrm{eq}\right)$ additional GHG has been released for transporting ethanol from the factory to 158 the asphalt plant. This result was observed from the EWMA mixtures prepared using 3\% and 5\% 
159 ethanol at both production temperatures, $80^{\circ} \mathrm{C}$ and $100^{\circ} \mathrm{C}$. The $\mathrm{CO}_{2}$ emissions during transportation of 160 raw materials only represent less than $10 \%$ of the total $\mathrm{CO}_{2}$ emitted from the asphalt production in the 161 asphalt pavement industry.

\section{$1644.2 \quad$ Cumulative Energy Demand in the Entire Life Cycle Period}

The total cumulative energy demand results are shown in Figs. 9 to 11. In general, HMA results

166 in the highest energy demand, followed by WWMA and EWMA as presented in Fig. 9. The application 167 of WMA technology has reduced the energy consumed during production of HMA, which are about $1681.96 \%$ and $2.93 \%$ using WWMA and EWMA respectively. Based on Fig. 10, each pavement presents a 169 similar trend, with more than 95\% of energy consumed during the lifetime of the pavements. From Fig. 17011 , it is clearly shown that the highest energy demand during the service life of asphalt pavement is 171 dominated by the manufacturing/placement of pavement. Based on the cumulative energy demand, the 172 WMA technique can be applied to support sustainable development by lowering the energy 173 consumption in asphalt pavement industry. Besides lowering the required energy for the heating and 174 mixing processes, WMA technology also results in lower aging factors that had significantly improved 175 the fatigue resistance of asphalt pavement [9], especially for the pavement placed in the hot climate 176 regions. However, additional attention should be factored in to avoid premature permanent deformation 177 especially at the beginning of service life [9].

1794.3 Global Warming Potential in the Entire Life Cycle Period

181 GWP 100a to compare the GHG emissions of HMA, WWMA and EWMA. The application of foamed 
182 WMA technologies has reduced the total $\mathrm{CO}_{2}$ emissions of HMA, which are about $5.65 \%$ and $9.13 \%$ 183 using WWMA and EWMA, respectively. The total GHG emissions result of each pavement type is 184 shown in Fig. 12.

From Fig. 13, it can be seen that the EWMA has the lowest $\mathrm{CO}_{2}$ emission compared to WWMA and HMA. However, there is no different in $\mathrm{CO}_{2}$ emissions in all pavements during the waste disposal stage. Overall, the $\mathrm{CO}_{2}$ emissions during the waste disposal stage only represent about $10 \%$ of the total $\mathrm{CO}_{2}$ emitted from "cradle" to "grave" in pavement industry. Fig. 14 further shows that the use of 190 EWMA results in the smallest environmental footprint compared to the application of HMA and 191 WWMA. Based on the amount of $\mathrm{CO}_{2}$ emissions during manufacturing and placement of asphalt 192 concrete, EWMA released about 8,000 and 21,000 $\mathrm{kgCO}_{2}$ less than WWMA and HMA respectively, 193 during the manufacturing/construction process.

At the end of service life, the asphalt pavements are typically milled from the road and can be either disposed in the sanitary landfill or reused as Reclaimed Asphalt Pavement (RAP). However, in this study all materials were assumed to be disposed into the sanitary landfill. The life cycle inventory of the disposal waste was selected from the Eco-invent database which was available in the SimaPro 7.3. Doka [14] stated that the inventory includes the environmental burdens, machinery and transportation, landfill leachate, emissions to air through landfill gas incineration, long term emission from landfill to 201 groundwater and treatment of leachate in wastewater treatment plants. Based on the result of this study 202 (Fig. 15), it was found that the highest amount of $\mathrm{CO}_{2}$ has been released by bitumen in the waste 203 disposal stage, about $64.47 \%$. This is due to the presence of a high amount of carbon molecules in the 204 asphalt binder compared to the other materials. Application of RAP material had significantly lowered 
205 the $\mathrm{CO}_{2}$ emissions, and also enhanced the performance of asphalt pavement. However, the disposal 206 process of aggregate has consumed the highest energy compared to asphalt binder and filler materials. 207 This is due to $93 \%$ of asphalt pavement being dominated by aggregate.

$209 \quad 4.4 \quad$ Eco-Indicator 95 Analysis

210 The environmental impacts of HMA, WWMA, and EWMA were evaluated using Eco-Indicator 21195 as tabulated in Table 5. This method is categorized as a technical, quantitative and / or qualitative 212 process to characterize the effects of environmental burdens identified in the LCA inventory. Vidal et al. 213 [15] mentioned that the contributions of every stage of the life cycle and waste disposal stages to the 214 overall impact varies depending on the types of asphalt pavement. Based on the overall results, the 215 impacts of EWMA are lower compared to WWMA and HMA pavements. This is due to the reduction of 216 manufacturing and construction temperatures, which are $30^{\circ} \mathrm{C}$ and $80^{\circ} \mathrm{C}$ lower compared to WWMA and 217 HMA, respectively. The major reduction can be seen through a significant reduction of GHG emissions, 218 acidification, eutrophication, and winter smog as well as energy resources. Besides that, WWMA had 219 performed better in term of heavy metals and carcinogen impacts; however the differences compared to 220 other pavement types are less than $2 \%$.

\section{$222 \quad$ 5. Conclusions}

223 Based on the cradle to gate analysis, several conclusions can be made:

224 1. The cumulative energy demand and GHG emission of each asphalt pavement is primarily 225 affected by the type and the quantity of material that is incorporated in the asphalt concrete. 226 Smaller energy consumption and GHG emission were noted when the EWMA manufactured at a $227 \quad$ lower temperature. 
2. The transportation of raw materials only consumed less than $10 \%$ of the energy compared to asphalt mixture production which dominated at least $90 \%$ of the total energy consumption from the cradle to gate stages. Meanwhile, more than $70 \%$ of GHG has been released during the manufacturing of raw material and asphalt mixture.

3. EWMA is a good alternative in replacing HMA and WWMA. However, from the result, the amount of ethanol should be limited to $3 \%$ to ensure the energy consumption is lower than the production of HMA.

236 Based on the cradle to grave analysis, several conclusions can be made:

237 1. Even though this study is not definitive, with regard to environmental performance, EWMA has performed better compared to WWMA and HMA.

2. Cumulative energy demand and GHG emissions for different asphalt pavements are primarily depending on the production temperature. Asphalt pavement manufactured at lower temperature requires a smaller amount of energy and lower GHG emission as shown by EWMA. The results indicate that more than $98 \%$ of energy was consumed during the pavement service life. Meanwhile, about $88 \%$ of GHG has been released during the pavement lifetime.

4. EWMA has a high potential to reduce the detrimental impacts from the asphalt industry based on Eco-Indicator 95 analysis, whereas it can lower the greenhouse gas emissions, ozone layer depletions, acidification, eutrophication, summer smog, winter smog and energy resources. 


\section{Recommendations for Future Works}

1. The energy consumptions used in heating/drying the materials also could be affected by the

\section{Acknowledgements}

This material is based in part upon work supported by the National Science Foundation under Grant

273 CMMI 1300286. Any opinions, findings, and conclusions or recommendations expressed in this 
274 material are those of the author's and do not necessarily reflect the views of the National Science

275 Foundation. The author also appreciated the valuable insight from Professor David Shonnard in the 276 Department of Chemical Engineering at Michigan Technological University.

278 References

279 1. Button, J.W., C. Estakhri, and A. Wimsatt, A Synthesis of Warm-Mix Asphalt. 2007, Texas $280 \quad$ Transportation Institute: Austin, Texas.

281 2. Kristjansdottir, O., Warm Mix Asphalt for Cold Weather Paving, in Civil and Environmental 282 Engineering. 2006, University of Washington: Seattle.

283 3. Little, D.N., J.W. Button, and J.A. Epps, Structural Properties of Laboratory Mixtures 284 Containing Foamed Asphalt and Marginal Aggregates. Transportation Research Record, 1983. 285911.

286 4. D’Angelo, J., et al., Warm Mix Asphalt: European Practice. 2008, Office of International 287 Programs, Office of Policy, Federal Highway Administration, U.S. Department of 288 Transportation, American Association of State Highway and Transportation Officials, National 289 Cooperative Highway Research Program.

290 5. Barthel, W., J.-P. Marchand, and M.V. Devivere. Warm Asphalt Mixes By Adding A Synthetic 291 Zeolite. in Eurasphalt \& Eurobitume Congress 2004 Proceedings. 2004.

292 6. Anderson, R.M., et al., Engineering Properties, Emissions, and Field Performance of Warm Mix 293 Asphalt Technology. 2008, National Cooperative Highway Research Program (NCHRP).

294 7. FHWA. Warm Mix Asphalt Technologies and Research. 2007 2007]; Available from: 295 http://www.fhwa.dot.gov/pavement/asphalt/wma.cfm. 
296 8. Abbas, A.R. and A. Ali, Mechanical Properties of Warm Mix Asphalt Prepard Using Foamed 297 Asphalt Binders. 2011, The University of Akron: Akron, Ohio.

298 9. Goh, S.W., Development and Improvement of Warm-mix Asphalt Technology. 2012, Michigan 299 Technological University.

300 10. Huang, Y., R. Bird, and O. Heidrich, Development of a life cycle assessment tool for 301 construction and maintenance of asphalt pavements. Journal of Cleaner Production, 2009. 17(2): 302 p. 283-296.

303 11. In, B.M. and M.A. Curran, Life-cycle assessment: inventory guidelines and principles. 1994: $304 \quad$ CRC Press.

305 12. Horvath, A. and C. Hendrickson, Steel versus steel-reinforced concrete bridges: Environmental 306 assessment. Journal of Infrastructure Systems, 1998. 4(3): p. 111-117.

307 13. Chehovits, J. and L. Galehouse. Energy usage and greenhouse gas emissions of pavement 308 preservation processes for asphalt concrete pavements. in Compendium of Papers from the First $309 \quad$ International Conference on Pavement Preservation. 2010.

310 14. Doka, G., Life Cycle Inventories of Waste Treatment Services. Final report ecoinvent 2000 No. 311 13. EMPA St. Gallen, Swiss Centre for Life Cycle Inventories, Dübendorf, CH. Online-Version 312 under: www. ecoinvent. ch, 2003.

313 15. Vidal, R., et al., Life cycle assessment of hot mix asphalt and zeolite-based warm mix asphalt 314 with reclaimed asphalt pavement. Resources, Conservation and Recycling, 2013. 74: p. 101-114. 


\section{List of Tables}

323 Table 1. List of foamed WMA technologies

324 Table 2. Transportation of raw material and mass of material required inputs

325 Table 3. Energy required for asphalt mixtures production processes and foaming agent pump

326 Table 4. Input required for the cradle to grave analysis

327 Table 5. Eco-indicator 95 analysis results 


\section{List of Figures}

346 Fig. 1. HMA system

347 Fig. 2. Foamed WMA system made with water or ethanol

348 Fig. 3. Location of material production companies and asphalt mixing plant

349 Fig. 4. Energy demand from raw material transportation

350 Fig. 5. Energy demand based on pavement types during production process

351 Fig. 6. Energy demand during raw material transportation and manufacturing of asphalt mixtures

352 Fig. 7. Total GHG emissions of each pavement types

353 Fig. 8. Comparison of $\mathrm{CO}_{2}$ emission during raw material transportation and manufacturing processes

354 Fig. 9. Energy demand based on pavement types

355 Fig. 10. Energy Demand during lifetime and waste disposal stage

356 Fig. 11. Energy demand categorized under transportation, manufacturing and maintenance processes

357 Fig. 12. Total GHG emissions of each pavement types

358 Fig. 13. Comparison of $\mathrm{CO}_{2}$ emission during lifetime and waste disposal stage

359 Fig. 14. $\mathrm{CO}_{2}$ emission observed in the transportation, construction and maintenance stages

360 Fig. 15. GHG emission and energy demand during waste disposal stage 
1 Table 1. List of foamed WMA technologies

\begin{tabular}{ccc}
\hline $\begin{array}{c}\text { Foaming Additives } \\
\text { or Technologies }\end{array}$ & Company & Recommended Dosage \\
\hline Aspha-min ${ }^{\circledR}$ & Eurovia and MHI & $0.3 \mathrm{wt} \%$ of asphalt concrete \\
\hline ADVERA ${ }^{2}$ WMA & PQ Corporation & $0.25 \mathrm{wt} \%$ of asphalt concrete \\
\hline WAM-Foam ${ }^{\circledR}$ & $\begin{array}{c}\text { KoloVeidekke Shell } \\
\text { Bitumen }\end{array}$ & $\begin{array}{c}\text { No additive required. Incorporating soft } \\
\text { and hard foamed binder }\end{array}$ \\
\hline LEA ${ }^{\circledR}$ & LEA-CO & $0.2-0.5 \mathrm{wt} \%$ of asphalt binder \\
\hline LEAB $\AA$ & BAM & $0.1 \% \mathrm{wt} \%$ of asphalt binder
\end{tabular}

2

3

4

5

6

7

8

9

10

11

12

13

14

15

16

17

18 
1 Table 2. Transportation of raw material and mass of material required inputs

\begin{tabular}{|c|c|c|c|c|}
\hline \multirow{2}{*}{ Process } & \multirow{2}{*}{ Item } & \multicolumn{3}{|c|}{ Pavement Type } \\
\hline & & HMA & WWMA & EWMA \\
\hline \multirow{4}{*}{$\begin{array}{c}\text { Transportation } \\
\text { of raw } \\
\text { material to } \\
\text { asphalt plant }\end{array}$} & Aggregate & $21422 \mathrm{~km}$ & $21422 \mathrm{~km}$ & $21422 \mathrm{~km}$ \\
\hline & Bitumen & $6207.9 \mathrm{~km}$ & $6207.9 \mathrm{~km}$ & $6207.9 \mathrm{~km}$ \\
\hline & Filler (Cement) & $172 \mathrm{~km}$ & $172 \mathrm{~km}$ & $172 \mathrm{~km}$ \\
\hline & $\begin{array}{c}\text { Foaming Agent } \\
\left(\mathrm{M}_{\mathrm{n} \%} / \sum \mathrm{M}\right) \times \text { Total } \\
\text { Distance }\end{array}$ & - & Tap water & $\begin{array}{l}1 \%: 25.7 \mathrm{~km} \\
3 \%: 77.1 \mathrm{~km} \\
5 \%: 129 \mathrm{~km}\end{array}$ \\
\hline \multirow{4}{*}{$\begin{array}{l}\text { Mass of } \\
\text { materials } \\
\text { required }\end{array}$} & Aggregate & $1708.88 \mathrm{t}$ & $1708.88 \mathrm{t}$ & $1708.88 \mathrm{t}$ \\
\hline & Binder PG58-28 & $101.06 \mathrm{t}$ & $101.06 \mathrm{t}$ & $101.06 \mathrm{t}$ \\
\hline & Filler (Cement) & $27.56 \mathrm{t}$ & $27.56 \mathrm{t}$ & $27.56 \mathrm{t}$ \\
\hline & Foaming Agent & - & $\begin{array}{l}1 \%: 1.01 \mathrm{t} \\
3 \%: 3.03 \mathrm{t} \\
5 \%: 5.05 \mathrm{t}\end{array}$ & $\begin{array}{l}1 \%: 1.01 \mathrm{t} \\
3 \%: 3.03 \mathrm{t} \\
5 \%: 5.05 \mathrm{t}\end{array}$ \\
\hline
\end{tabular}

2

3

4

5

6

7

8

9

10

11

12

13

14

15 
1 Table 3. Energy required for asphalt mixtures production processes and foaming agent pump

\begin{tabular}{ccccc}
\hline Foaming Agents & $\begin{array}{c}\text { Production } \\
\text { Temperature }\left({ }^{\circ} \mathrm{C}\right)\end{array}$ & $\begin{array}{c}\text { Composition } \\
\text { (Based on Mass } \\
\text { of Asphalt } \\
\text { Binder) }\end{array}$ & $\begin{array}{c}\text { Energy Required } \\
\text { for Production } \\
\text { Process (GJ) }\end{array}$ & $\begin{array}{c}\text { Energy Required } \\
\text { for Foaming } \\
\text { Agent Pump } \\
(\mathrm{kwh})\end{array}$ \\
\hline \multirow{3}{*}{ Water } & \multirow{2}{*}{110} & $1 \%$ & 297.10 & 2.49 \\
& & $3 \%$ & 297.43 & 7.48 \\
& \multirow{2}{*}{130} & $5 \%$ & 297.76 & 12.48 \\
\hline \multirow{3}{*}{ Ethanol } & \multirow{2}{*}{80} & $3 \%$ & 430.21 & 2.49 \\
& & $5 \%$ & 430.68 & 7.48 \\
& \multirow{2}{*}{100} & $3 \%$ & 431.16 & 12.48 \\
\hline & & $5 \%$ & 176.13 & 3.21 \\
& & $1 \%$ & 176.32 & 9.63 \\
& & $3 \%$ & 254.03 & 16.04 \\
\hline
\end{tabular}

2

3

4

5

6

7

8

9

10

11

12

13

14

15 
1 Table 4. Input required for the cradle to grave analysis

\begin{tabular}{|c|c|c|}
\hline Process & Item & Input \\
\hline Total Distance for Transporting material to site & Asphalt Mixture & $656.3 \mathrm{~km}$ \\
\hline \multirow{3}{*}{ Placement of Pavement } & HMA & $16.54 \mathrm{GJ}$ \\
\hline & WWMA & $15.99 \mathrm{GJ}$ \\
\hline & EWMA & $13.78 \mathrm{GJ}$ \\
\hline \multirow{3}{*}{ Pavement rehabilitation } & Aggregate & $315 \mathrm{t}$ \\
\hline & Emulsion & $34.5 \mathrm{t}$ \\
\hline & Energy for the machineries & $133.5 \mathrm{GJ}$ \\
\hline \multirow{3}{*}{ Waste scenario } & Aggregate & $92.5 \%$ \\
\hline & Asphalt Binder & $6.2 \%$ \\
\hline & Filler (Cement) & $1.3 \%$ \\
\hline
\end{tabular}

2

3

4

5

6

7

8

9

10

11

12

13

14

15

16

17 
1 Table 5. Eco-indicator 95 analysis results

\begin{tabular}{ccccc}
\hline \multirow{2}{*}{ Impact category } & \multirow{2}{*}{ Unit } & \multicolumn{3}{c}{ Type of Asphalt Concrete } \\
\cline { 3 - 5 } & & $\mathrm{HMA}$ & WWMA & EWMA \\
\hline Greenhouse & $\mathrm{kg} \mathrm{CO}_{2}$ & 210015.4 & 192858.3 & $\mathbf{1 8 8 6 5 1 . 8}$ \\
\hline Ozone layer & $\mathrm{kg} \mathrm{CFC}_{11}$ & 0.152169 & 0.149301 & $\mathbf{0 . 1 4 8 4 8 1}$ \\
\hline Acidification & $\mathrm{kg} \mathrm{SO}_{2}$ & 1513.263 & 1282.78 & $\mathbf{1 2 1 5 . 0 8}$ \\
\hline Eutrophication & $\mathrm{kg} \mathrm{PO}_{4}$ & 1076.221 & 1036.607 & $\mathbf{1 0 3 6 . 0 0 2}$ \\
\hline Heavy metals & $\mathrm{kg} \mathrm{Pb}$ & 8.905603 & $\mathbf{8 . 8 4 2 8 1 4}$ & 8.849174 \\
\hline Carcinogens & $\mathrm{kg} \mathrm{B}(\mathrm{a}) \mathrm{P}$ & 0.010013 & $\mathbf{0 . 0 0 9 8 4 4}$ & 0.009928 \\
\hline Summer smog & $\mathrm{kg} \mathrm{C} \mathrm{H}_{4}$ & 259.9898 & 249.3126 & $\mathbf{2 4 5 . 8 9 1 8}$ \\
\hline Winter smog & $\mathrm{kg} \mathrm{SPM}$ & 634.2758 & 567.1177 & $\mathbf{5 4 6 . 9 6 3 7}$ \\
\hline Energy resources & $\mathrm{MJ} \mathrm{LHV}$ & 9203450 & 8948158 & $\mathbf{8 9 3 3 1 1 2}$ \\
\hline
\end{tabular}

2 


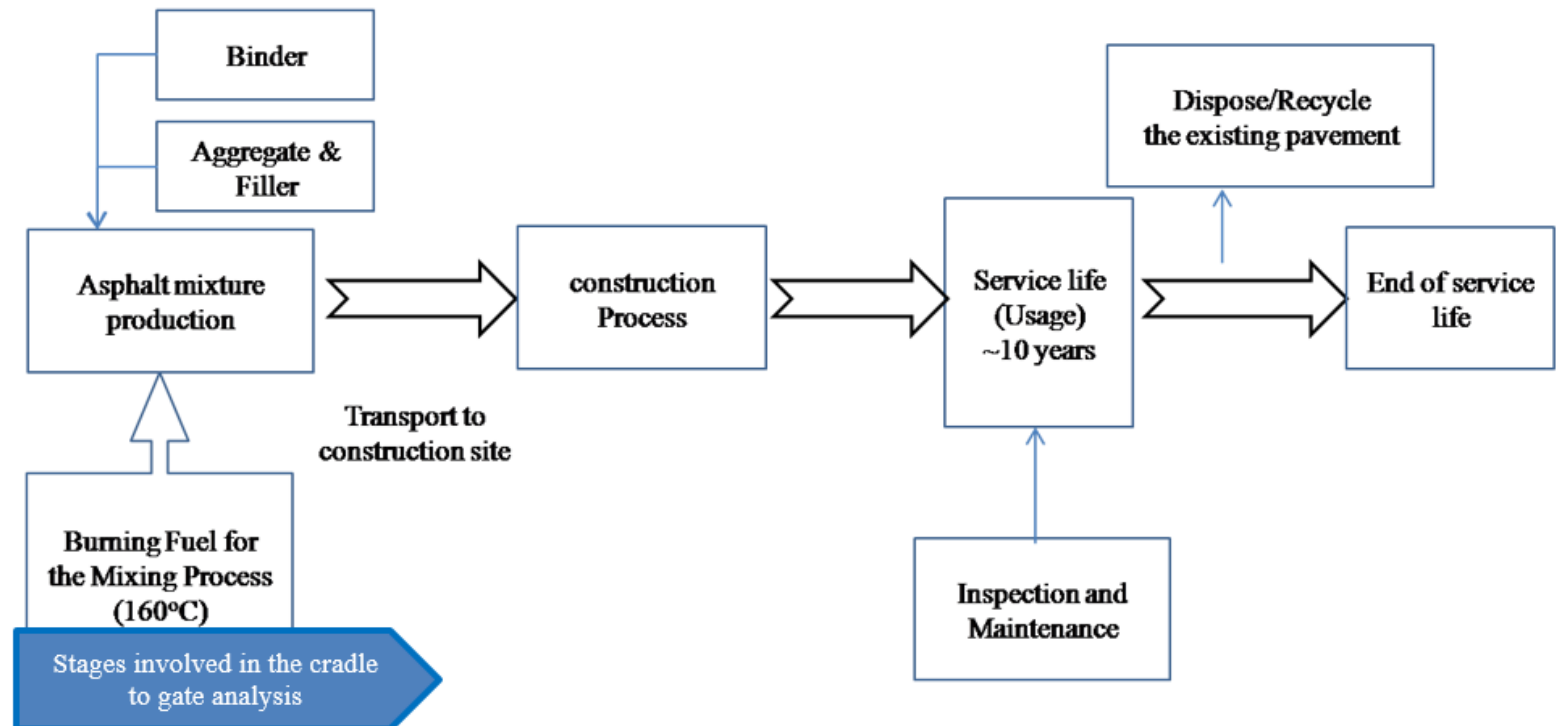

Fig. 1. HMA system

3

4 


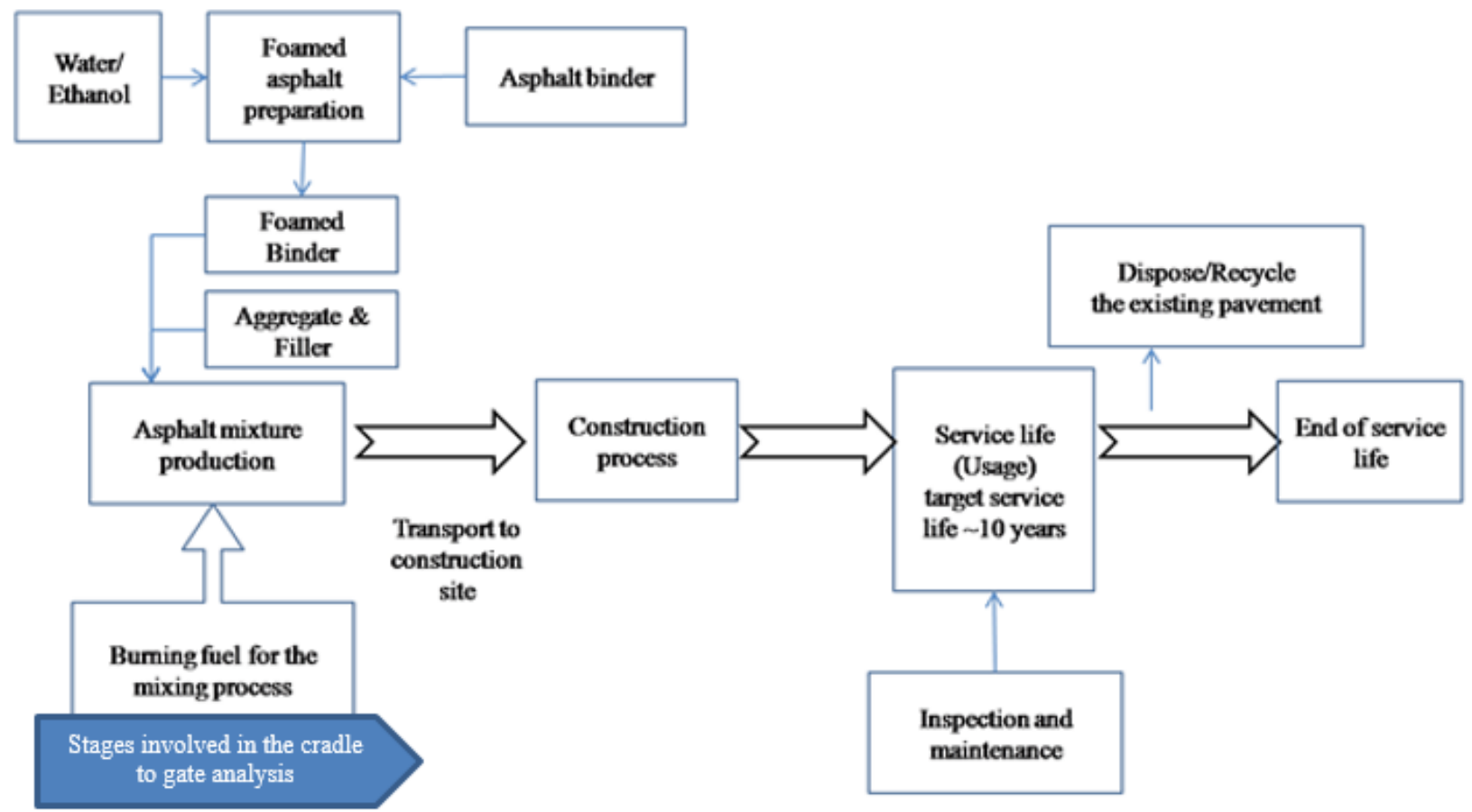

\section{Stages involved in the cradle to grave analysis}

Fig. 2. Foamed WMA system made with water or ethanol

3

4

5

6

7

8

9

10

11

12

13 


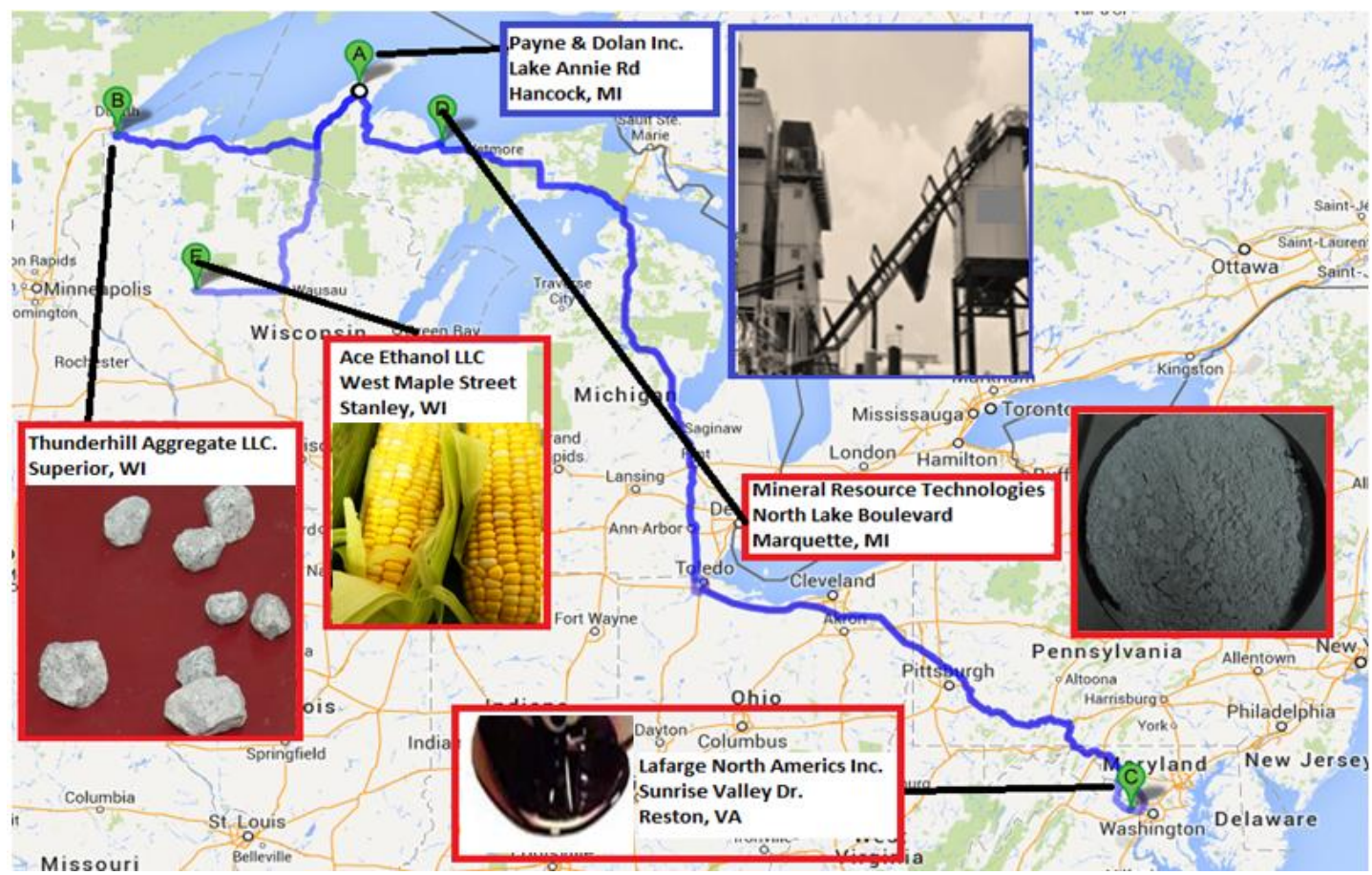

Fig. 3. Location of material production companies and asphalt mixing plant

4

5

6

7

8

9 


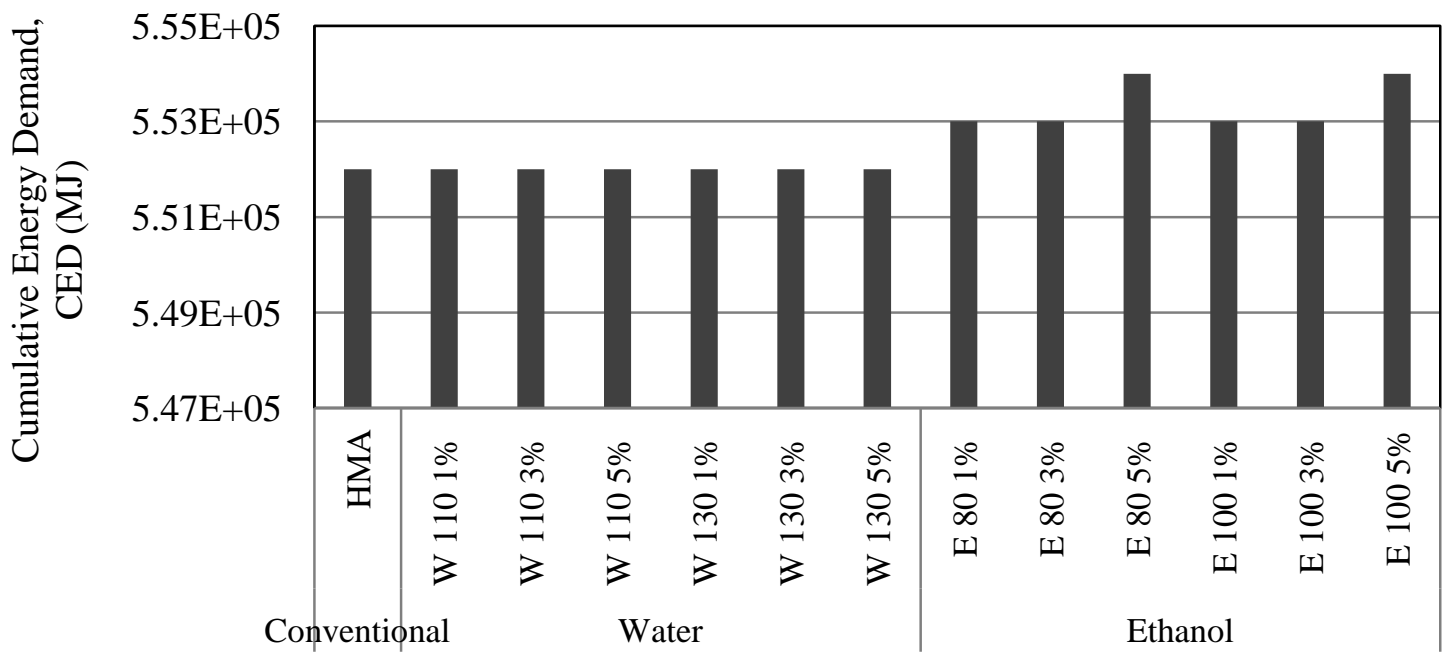

1

Fig. 4. Energy demand from raw material transportation

3

4

5

6

7

8

9

10

11

12

13

14

15

16 


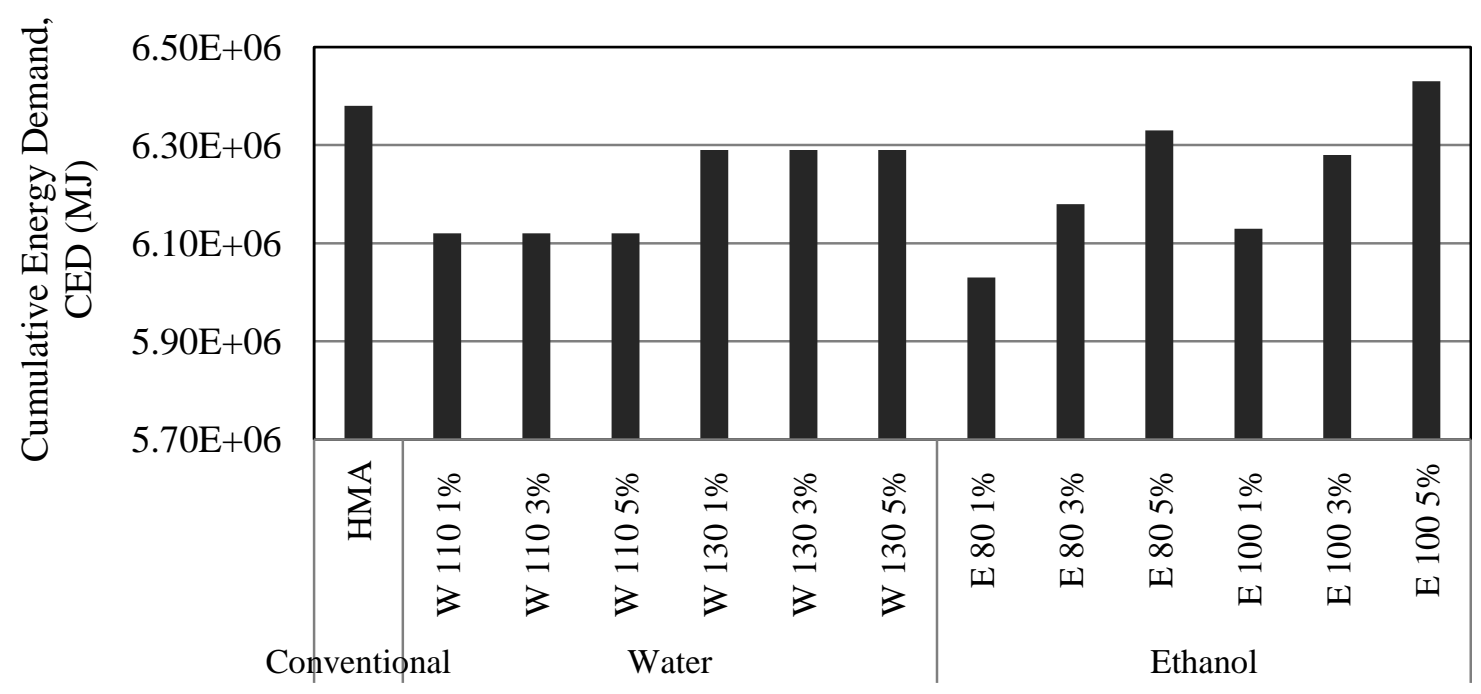

1 2

Fig. 5. Energy demand based on pavement types during production process

3

4

5

6

7

8

9

10

11

12

13

14

15

16 


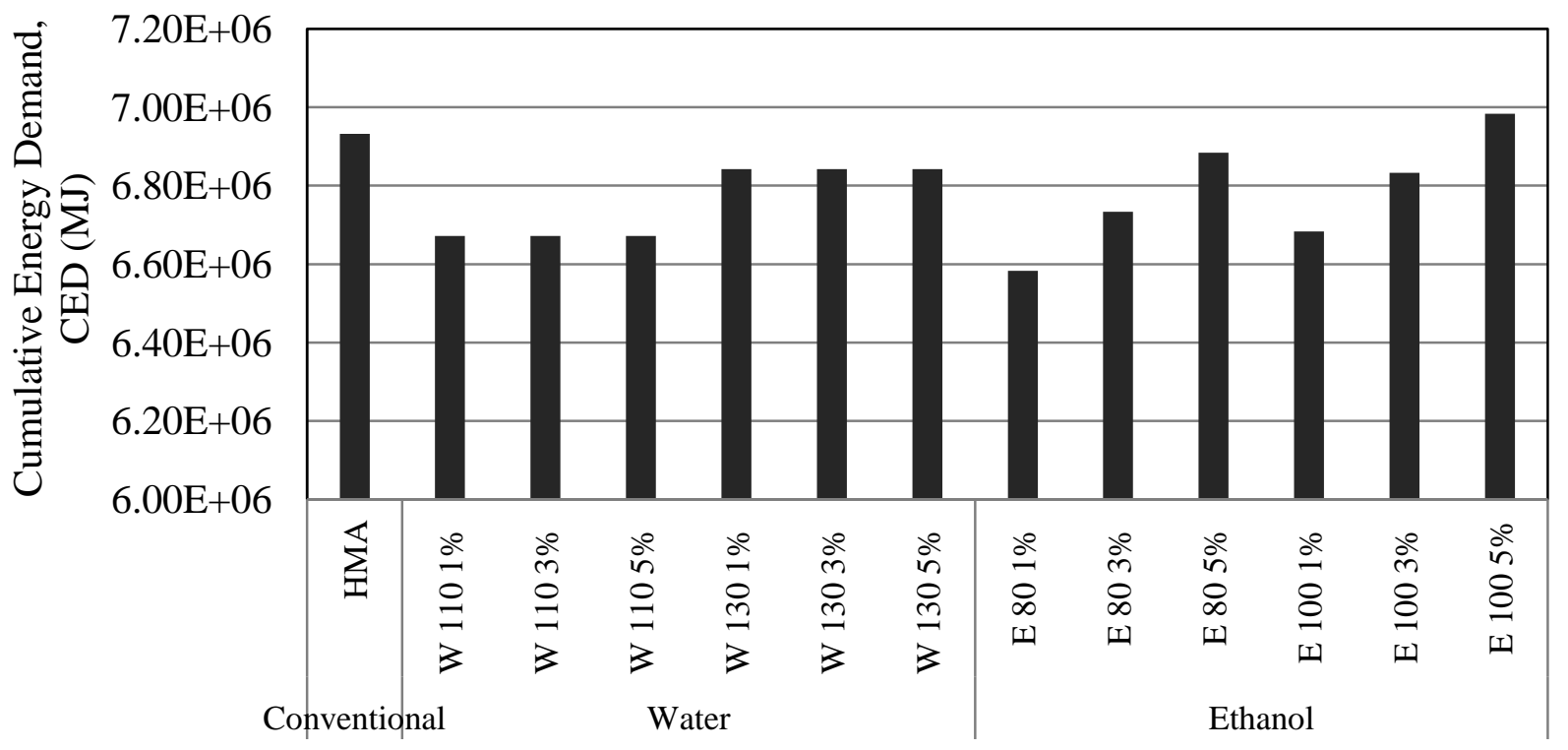

1

Fig. 6. Energy demand during raw material transportation and manufacturing of asphalt mixtures

3

4

5

6

7

8

9

10

11

12

13

14

15 


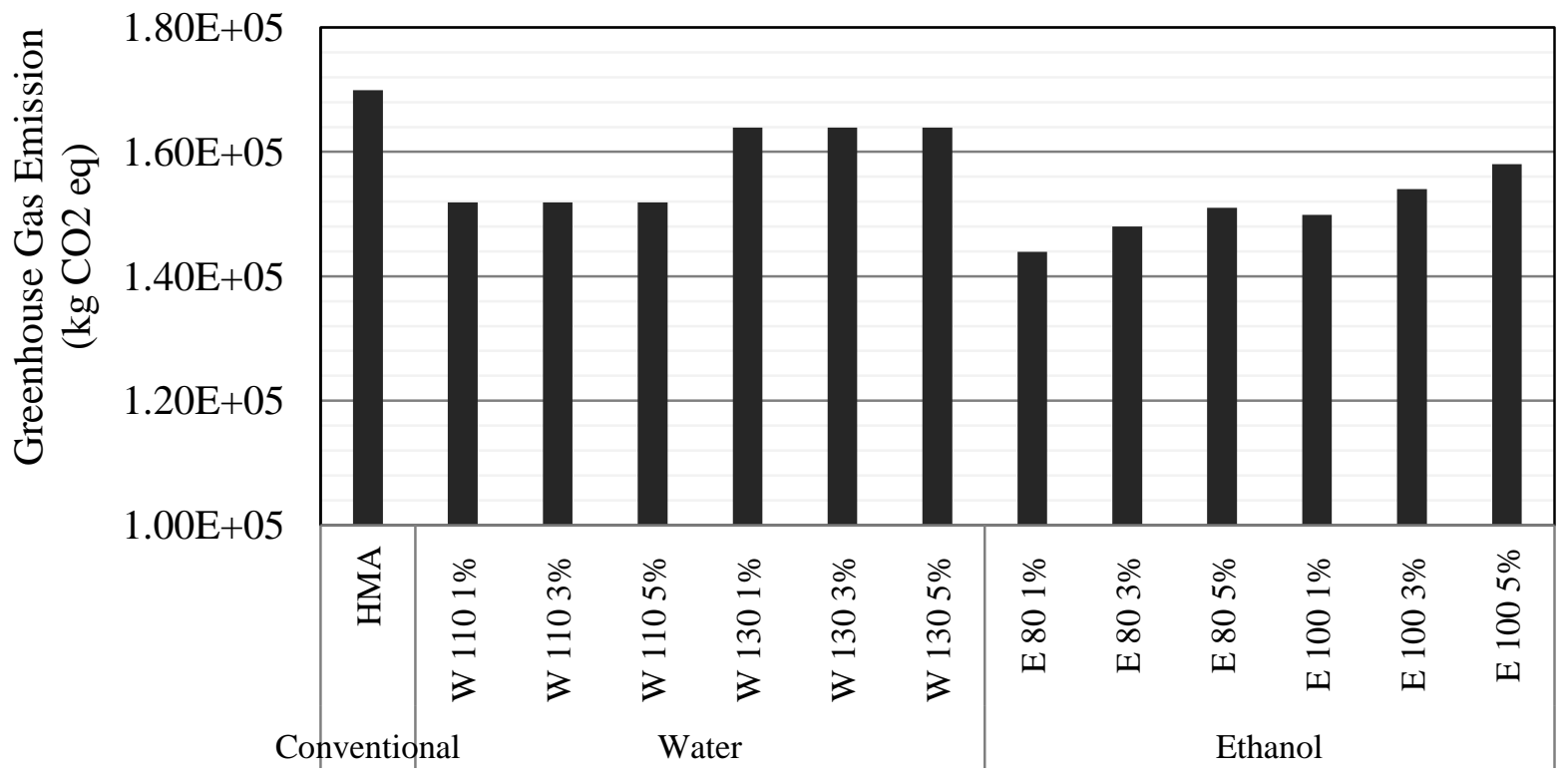

1

Fig. 7. Total GHG emissions of each pavement types

3

4

5

6

7

8

9

10

11

12

13

14

15 


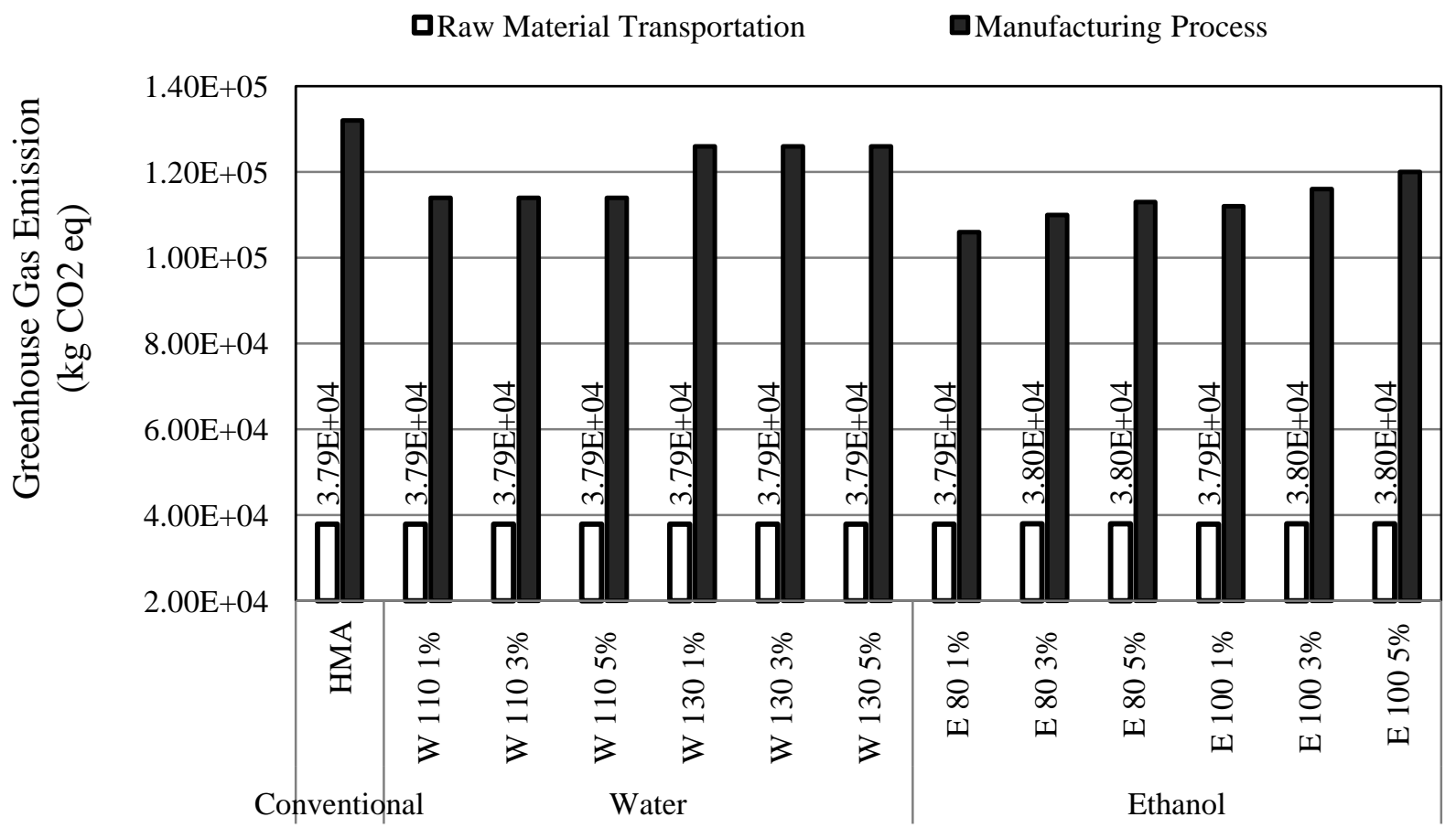

Fig. 8. Comparison of $\mathrm{CO}_{2}$ emission during raw material transportation and manufacturing processes 3 4 5 6 7 8 9 


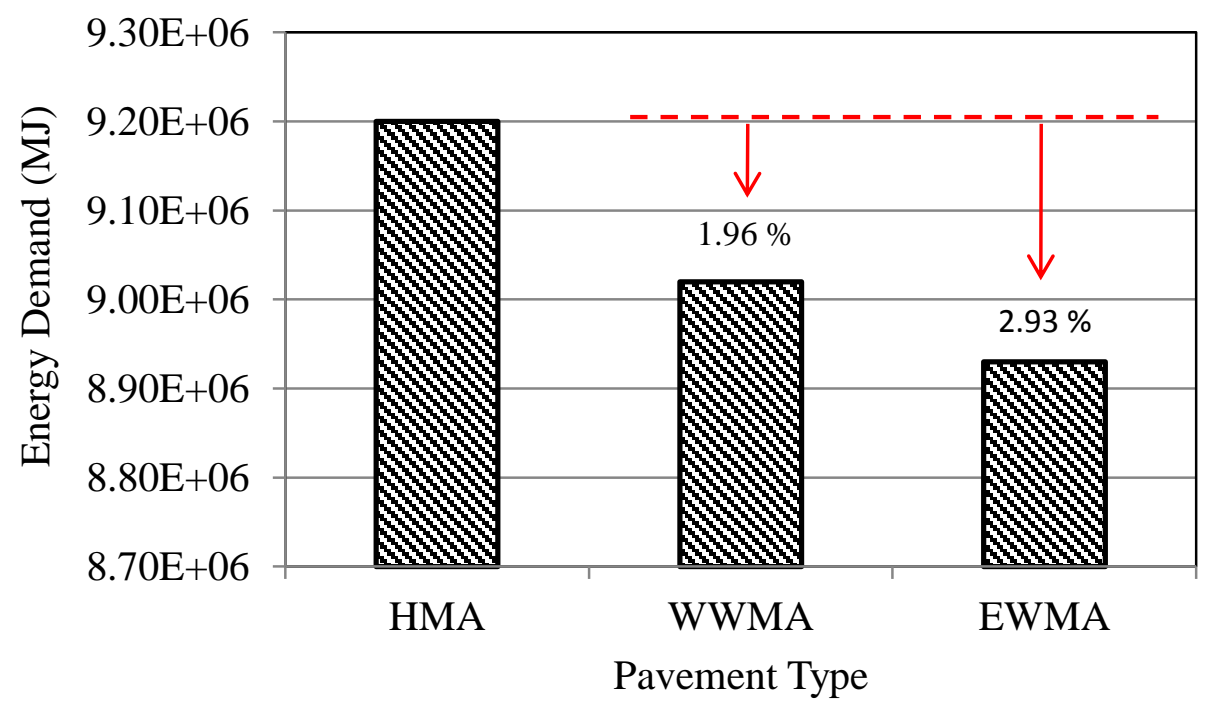

1

Fig. 9. Energy demand based on pavement types

3

4

5

6

7

8

9

10

11

12

13

14 


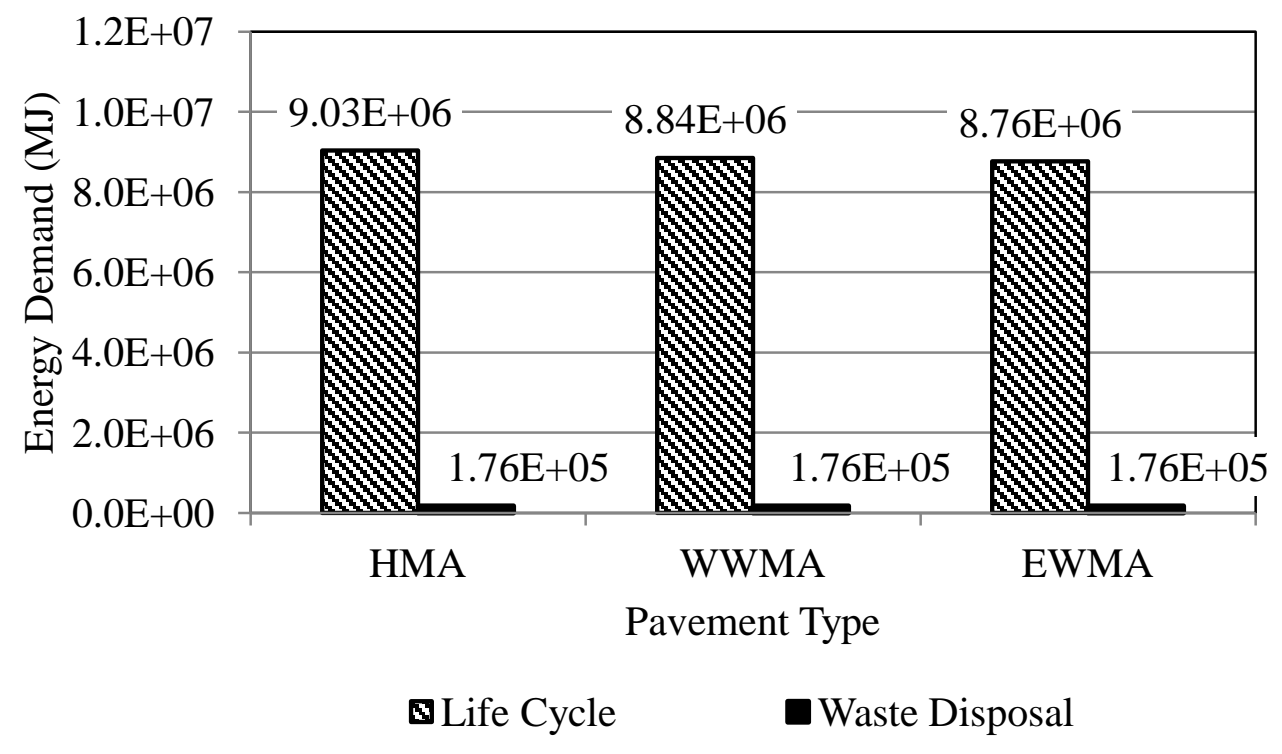

Fig. 10. Energy Demand during lifetime and waste disposal stage

6

7

8

9

10

11

12

13

14

15 


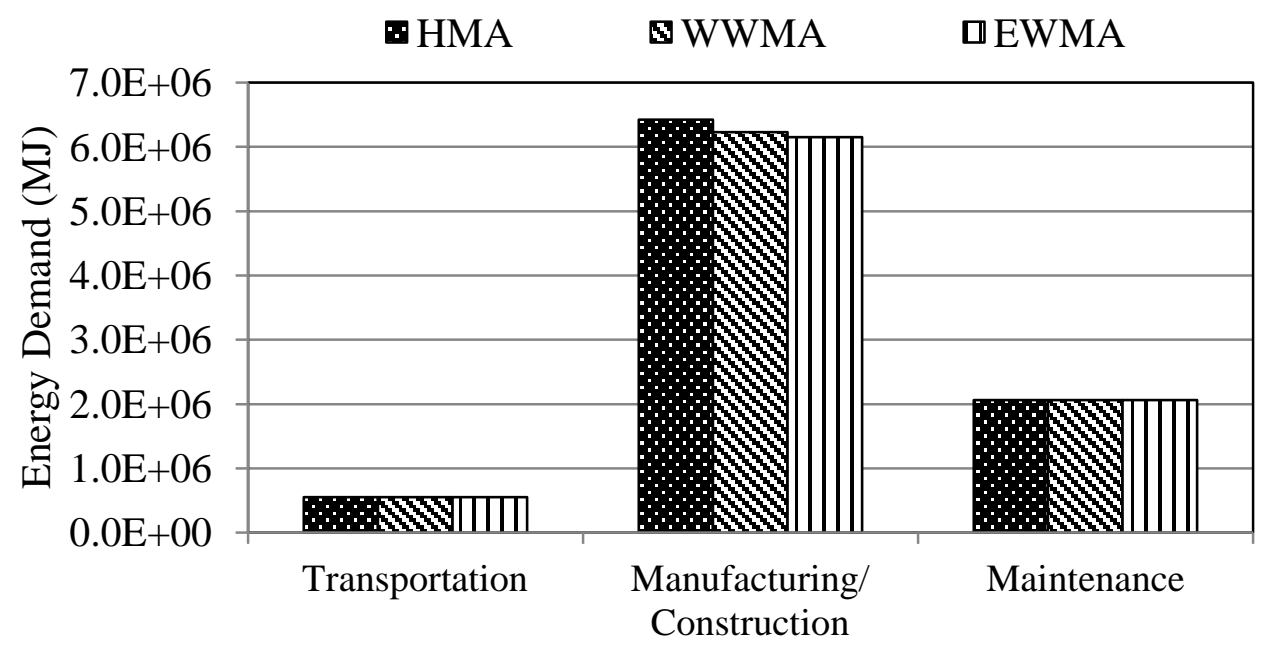

Pavement Type

$2 \quad$ Fig. 11. Energy demand categorized under transportation, manufacturing and maintenance processes

3

4

5

6

7

8

9

10

11

12

13

14

15

16 


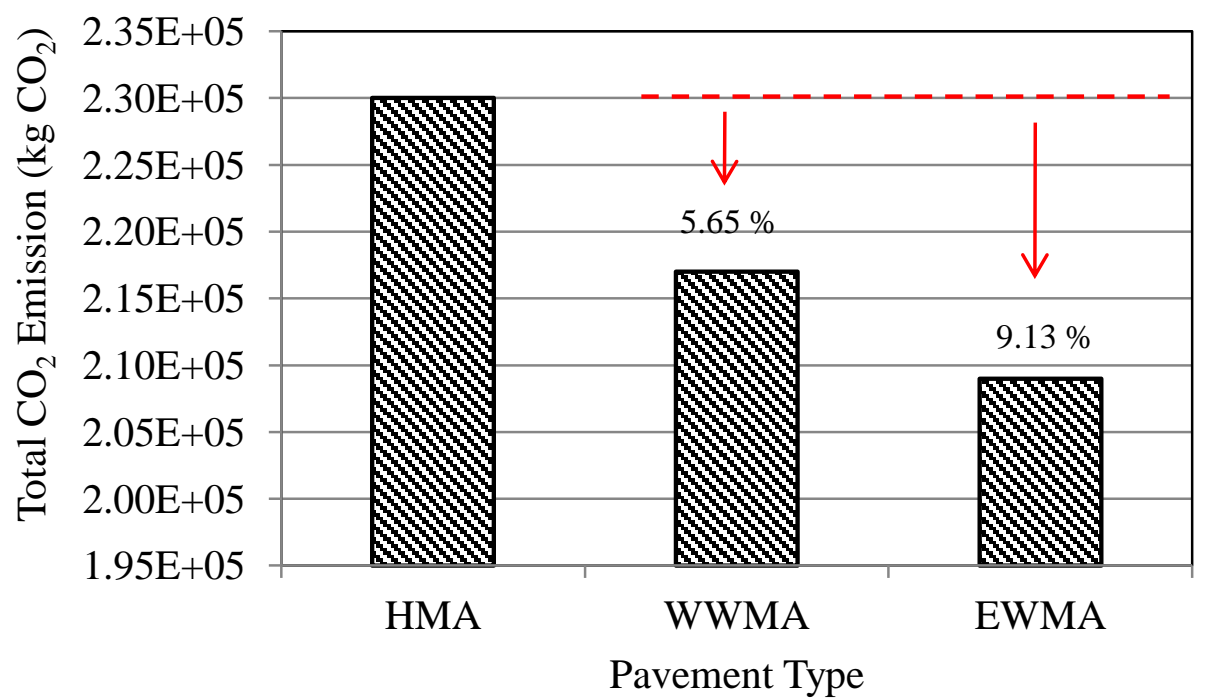

1

Fig. 12. Total GHG emissions of each pavement types

3

4

5

6

7

8

9

10

11

12

13

14

15

16 


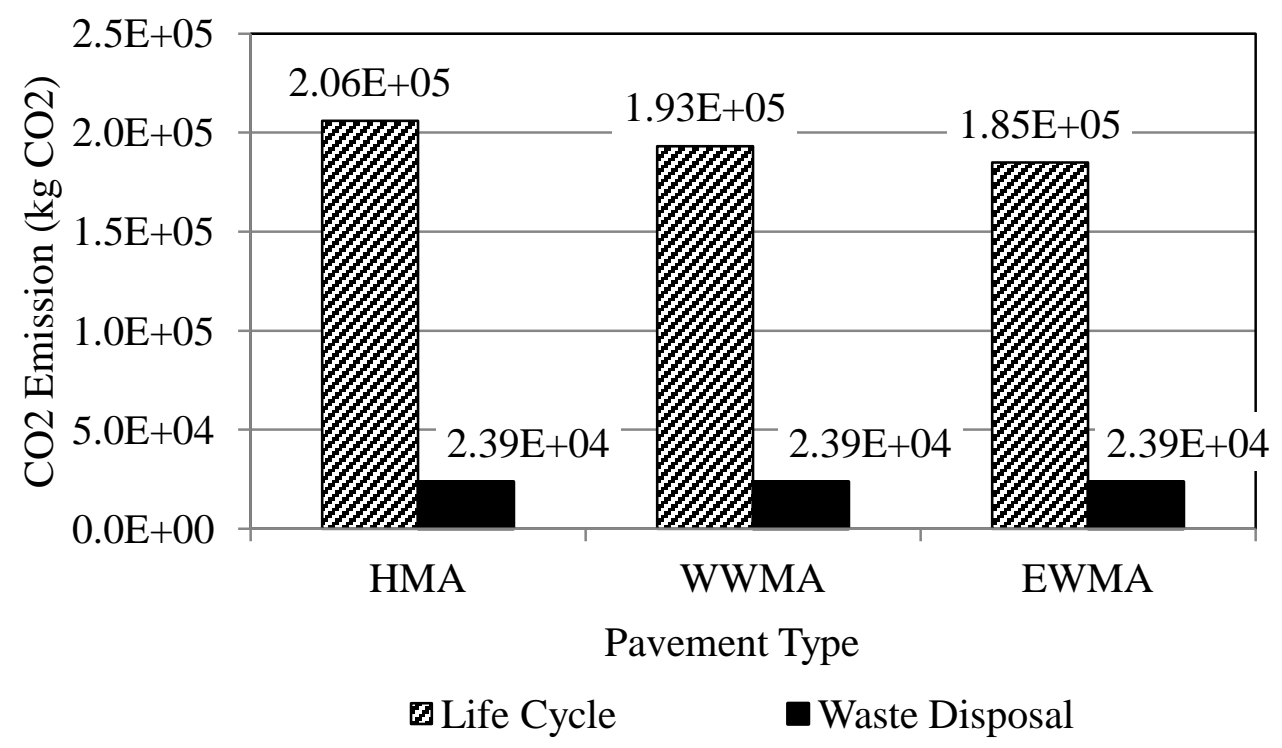

Fig. 13. Comparison of $\mathrm{CO}_{2}$ emission during lifetime and waste disposal stage 3

4

5

6

7

8

9

10

11

12

13

14

15

16 


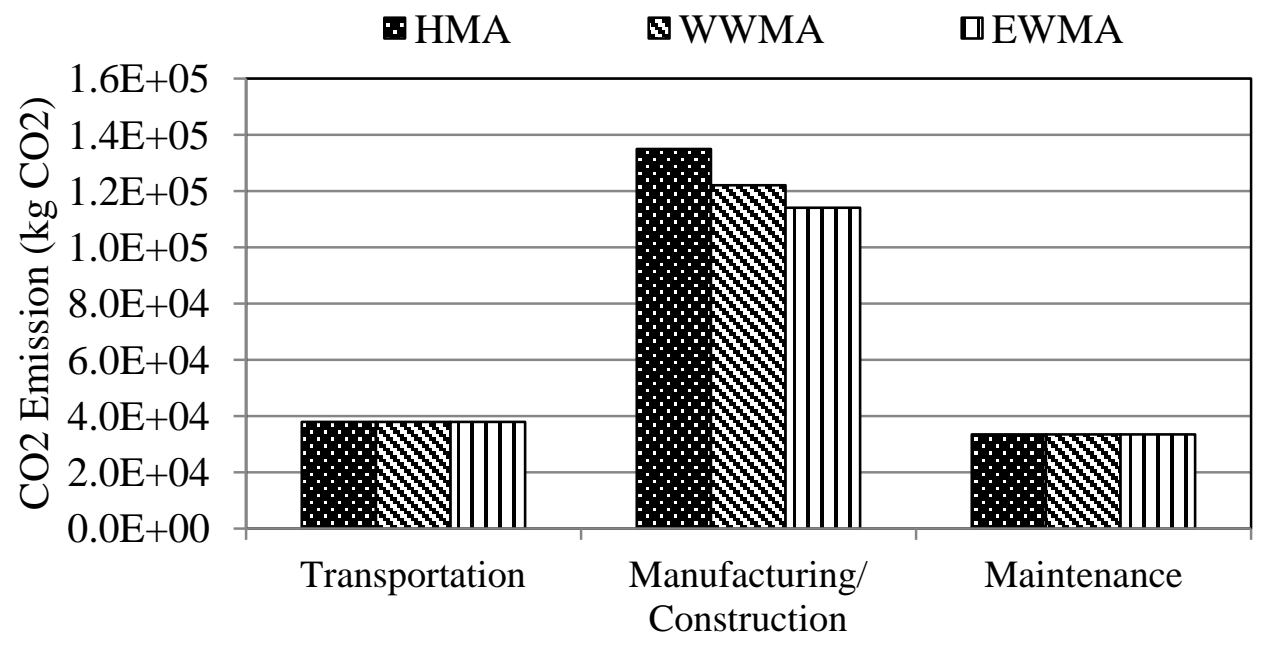

Pavement Type

Fig. 14. $\mathrm{CO}_{2}$ emission observed in the transportation, construction and maintenance stages

3

4

5

6

7

8

9

10

11

12

13

14

15

16 


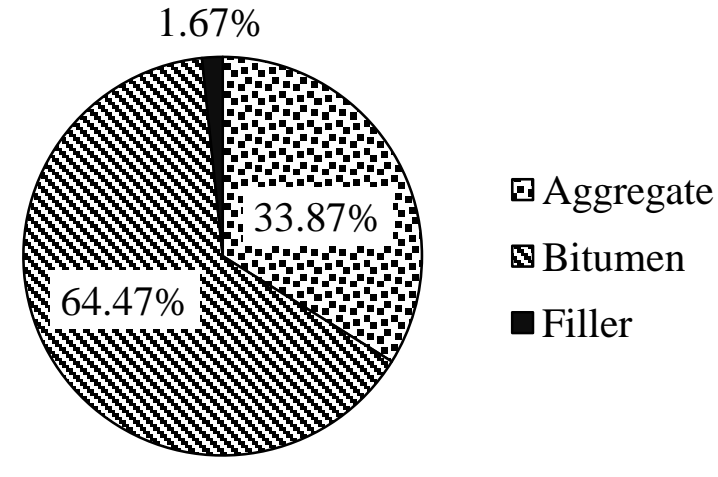

(a) Greenhouse Gas Emission

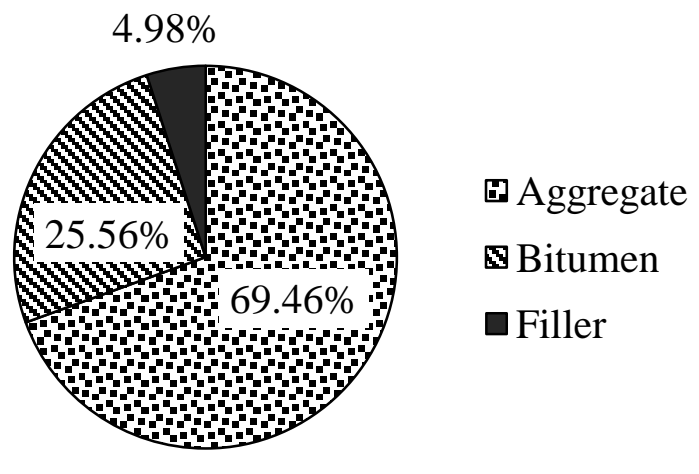

(b) Energy Demand

Fig. 15. GHG emission and energy demand during waste disposal stage 